\title{
Analisis Video Comments to Video Views Ratio Tiktok Pada 5 Gaming Creator Yang Menginspirasi
}

\author{
I Made Agus Rahbaja \\ imarkesiman@gmail.com
}

\begin{abstract}
TikTok is a social media application launched by ByteDance. TikTok allows users to create short videos accompanied by various kinds of music and filters. In Indonesia, there are 30.7 million active users, making Indonesia the country with the largest TikTok users in the world. With so many TikTok users, there are also many business opportunities that can be used on this social media platform, one of which is self-promotion. There are 5 Gamer accounts, namely: Archer Perez, Aya Ezmaria, RamenStyle PH, KrisRey, Chuplak. The purpose of this study is to calculate the credibility of the performance of 5 inspiring TikTok Gamer accounts. The method used for this research is quantitative exploratory method. The results of this study indicate that Aya Ezmaria is ranked first and has good account performance credibility.
\end{abstract}

\begin{abstract}
ABSTRAK
TikTok adalah aplikasi sosial media yang diluncurkan oleh ByteDance. TikTok memungkinkan pengguna untuk membuat video berdurasi singkat yang disertai dengan berbagai macam musik dan filter. Di Indonesia terdapat 30,7 juta pengguna yang aktif sehingga menjadikan Indonesia sebagai negara dengan pengguna TikTok terbesar di dunia. Dengan banyaknya pengguna TikTok sangat banyak maka banyak juga peluang usaha yang bisa digunakan dalam platform social media ini, salah satunya adalah mempromosikan diri. Adapun 5 akun Gamer, yaitu: Archer Perez, Aya Ezmaria, RamenStyle PH, KrisRey, Chuplak. Tujuan dari penelitian ini yaitu untuk menghitung kredibilitas dari performa 5 akun TikTok Gamer yang menginspirasi. Metode yang digunakan untuk penelitian ini yaitu metode eksploratif kuantitatif. Hasil dari penelitian ini menunjukan bahwa Aya Ezmaria mendapatkan peringkat pertama dan memiliki kredibilitas performa akun yang baik.
\end{abstract}

Keyword: Credibility Account TikTok ; Social Media Marketing ; Social Media TikTok ; Video Comments to Video Views Ratio; Gaming Creator 


\section{Pendahuluan}

Pada era revolusi industri 4.0 yang sudah sangat maju dan berkembang dengan pesat seperti saat ini, teknologi digital pun juga berkembang dengan sangat pesat dan tak terduga. Salah satu perkembangan teknologi yang paling kita rasakan kehadirannya adalah internet. Internet membuat semuanya terlihat lebih mudah, dari yang awalnya serba rumit, sekarang dapat diselesaikan dengan sangat mudah hanya dengan sekali klik saja. Segala hal yang dahulu dianggap susah bahkan cenderung mustahil pun kini bisa dilakukan melalui internet. Teknologi digital saat ini seperti menjadi salah satu hal pokok yang sangat penting bagi kehidupan umat millenial. Pada era ini banyak sekali terdapat hal-hal yang dapat dilakukan dengan teknologi, salah satu contohnya adalah untuk berkreasi dan berkomunikasi.

Media sosial tidak hanya digunakan sebagai alat untuk berkomunikasi dan berinteraksi, tetapi juga sebagai alat ekspresi diri (self expression) dan pencitraan diri (self branding). Seiring dengan kemajuan teknologi, maka banyaknya media yang dapat digunakan manusia untuk dijadikan alat dalam berkomunikasi, demikian pula dengan media sosial diantaranya untuk berbagi pesan dengan banyak pengguna media sosial itu sendiri, yaitu berupa berita (informasi), gambar (foto), dan juga video. Media sosial pun juga merupakan wadah yang mampu menciptakan bermacam bentuk komunikasi dan pemberian berbagai macam informasi bagi semua kalangan masyarakat tanpa memandang kalangan mana maupun statusnya apa. Dengan media sosial setiap individu dapat berkomunikasi dan berbagi informasi-informasi kepada semua kalangan masyarakat (Cakra 2021).

Tujuan utama TikTok adalah untuk video seluler berdurasi pendek, telah menjadi surga di mana para gamer dan streamer game dapat berbagi dan melihat konten kreatif yang terkait dengan game favorit mereka. Dengan video berdurasi pendek, pembuat game dapat fokus pada momen tertentu dalam game, mulai dari pertarungan epik hingga pembunuhan monster, dan bahkan menyoroti pemain dan karakter yang mereka sukai. TikTok juga memudahkan siapa saja untuk membuat konten yang menghibur dan menarik yang menunjukkan hasrat mereka, dengan bantuan alat pengeditan yang mudah digunakan dan membantu meningkatkan kreativitas (Castillo 2021).

Penelitian ini menggunakan metode eksploratif kuantitatif, dan akan menghitung menggunakan rasio-rasio yang ada pada TikTok. Pada penelitian (Purnamasari and Tutiasri 2021) menjelaskan bahwa terdapat 17 rasio yang ada pada sosial media TikTok dan relevan digunakan sebagai media ukur kredibilitas akun yang ada. Penelitian ini hanya berfokus untuk menghitung kredibilitas Video Comments to Video Views Ratio pada Top 5 Gaming Creator. Tujuan dari penelitian ini adalah mengetahui kredibilitas performa dari akun TikTok Top 5 Gaming Creator menggunakan Video Comments to Video Views Ratio.

\section{TINJAUAN PUSTAKA}

TikTok diluncurkan di China pada September 2016. TikTok dengan cepat mulai mendapatkan daya tarik di China dan perusahaan induk ByteDance meluncurkan versi internasional pada tahun berikutnya. Awalnya diluncurkan sebagai platform berbagi video berdurasi pendek, terutama untuk video lipsync dan menari, TikTok telah berkembang menjadi layanan video yang lengkap, dengan konten yang tersedia untuk semua jenis pemirsa (Iqbal 2021). 
TikTok menjadi aplikasi paling populer pada 2019 dan 2020. Diunduh 693 juta kali pada 2019 dan 850 juta kali pada 2020. Meski baru diluncurkan pada 2017, TikTok menjadi aplikasi ketujuh yang paling banyak diunduh pada 2010-an. dan tampaknya menjadi pesaing sejati melawan cengkeraman Facebook di jejaring sosial di Barat. Bahkan dengan pertumbuhan bintang ini, TikTok telah menghadapi beberapa kontroversi. Pada 2019, India dan Pakistan melarangnya karena "masalah moralitas", dengan kedua larangan tersebut dicabut setelah beberapa saat. India melarang aplikasi itu lagi pada Juni 2020, bersama dengan serentetan aplikasi berbasis China lainnya, karena ketegangan antara China dan India meningkat (Iqbal 2021).

Di Indonesia sendiri tren TikTok sangatlah menjamur. Digunakan sebagai sarana hiburan, digital marketing, informasi dan lain lain. Untuk mempermudah pengguna dalam penggunaan aplikasi, TikTok mengeluarkan berbagai fitur menarik. Fitur TikTok yang dapat digunakan oleh pengguna TikTok yakni musik, stiker, efek, status teks, pengubah suara, filter, dan alat pengatur waktu atau timer. Fitur dan fungsi aplikasi TikTok yang terbilang cukup banyak ini membuat aplikasi ini termasuk lima aplikasi teratas di google play store dan app store (Maharani 2021).

Sekarang TikTok sudah menjadi salah satu video plaform yang sangat besar dan populer di internet. Dengan kepopulerannya, TikTok menjadi sarana yang sangat bagus untuk digital marketing. Karena kemudahan dalam menggunakan aplikasi ini sehingga banyak orang yang tertarik menggunakannya, dengan banyaknya pengguna maka akan sangat mudah menyisipkan video promosi dari produk atau jasa. Sama halnya dengan Instagram, TikTok juga menjadi tempat sempurna untuk mempromosikan content creator sendiri untuk mencari popularitas.

\section{METODE PENELITAN}

Penelitian ini menggunakan metode eksploratif kuantitatif untuk mengetahui kredibilitas dari performa 5 akun TikTok Gamer yang menginspirasi Q1 2021. Metode eksploratif merupakan penelitian yang memiliki tujuan untuk melakukan eksplorasi atau memperdalam pengetahuan ataupun ide-ide baru mengenai suatu hal yang baru, guna merumuskan permasalahan secara terperinci (Maryam, Nur Aeni, and Studi PGSD Kampus Sumedang Jalan Mayor Abdurachman No 2016).

Tujuan dari penelitian ini yaitu mengetahui nilai kredibillitas dari performa 5 akun TikTok Gamer yang menginspirasi Q1 2021. Ada beberapa langkah yang harus dilakukan dalam penelitian ini, sehingga mampu menemukan peringkat pertama akun TikTok Gamer yang memiliki performa terbaik. Langkah-langkah yang dilakukan pada penelitian ini, diantaranya yaitu:

\section{Melakukan Eksplorasi Pada Website Untuk Menentukan Objek yang Akan Dianalisa.}

Eksplorasi ini dilakukan pada beberapa halaman website yang menyediakan informasi mengenai objek yang akan di teliti. Setelah ekslorasi selesai dilakukan, sehingga ditemukan nama-nama gamer yang akan dijadikan objek analisa. Setelah melakukan eksplorasi pada halaman website, maka langkah selanjutnya yaitu mencari nama akun 
TikTok dari masing-masing ganer. Pastikan semua gamer memiliki akun pada aplikasi sosial media TikTok.

\section{Menghitung Nilai Rata-Rata Variable Dari Top 5 Vendor Smartphone di Indonesia.}

Pada langkah ini, peneliti menghitung nilai variable video comments dan variable video views. Variabel merupakan sesuatu yang memiliki nilai bervariasi dimana nilai tersebut dapat dijadikan sebagai dasar untuk empat data yang berbeda seperti rasio, skala, ordinal, nominal dan internal. Untuk menghitung nilai rata-rata dari variabel video comments dan variabel video views yaitu dengan cara mengambil minimal 10 postingan kemudian di hitung sehingga menemukan nilai rata-rata dari masing-masing variabel.

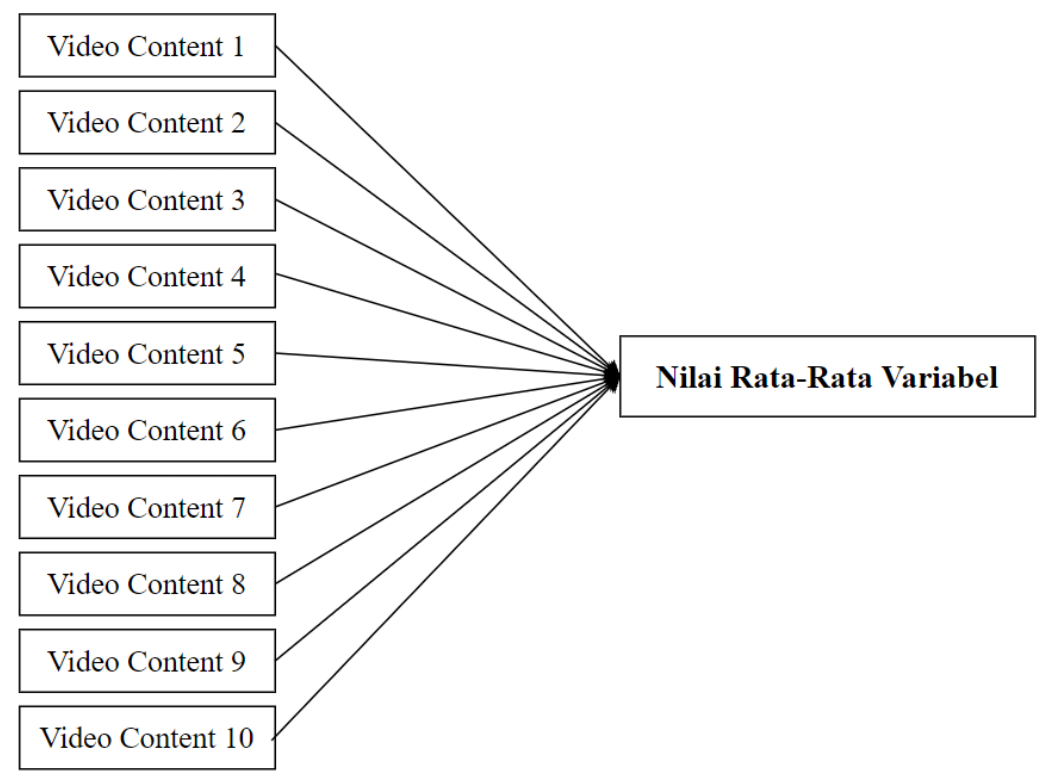

Gambar 1. Analisa Nilai Rata-Rata Variabel.

\section{Menghitung Nilai Kredibilitas Rasio}

Untuk menghitung nilai kredibilitas dari video comments to video views ratio, peneliti menggunakan cara membagi nilai variabel pertama dengan nilai variabel kedua. Jika video comments memiliki nilai 100 dan video views memiliki nilai 300, maka cara menghitungnya yaitu $100: 300=0,3$. Dengan begitu nilai dari video comments to video views ratio adalah 0,3 .

\section{Menentukan Peringkat Pada Akun TikTok}

Pada langkah terakhir yang dilakukan pada penelitian ini yaitu menentukan peringkat pada masing-masing rasio yang ada. Pada penentuan peringkat perlu melihat karakteristik dari rasio yang di teliti. Jika karakteristik rasio merupakan rendah, maka objek yang memiliki nilai terendah akan mendapatkan angka 5 dan objek yang memiliki nilai tertinggi akan mendapatkan angka 1. Namun jika rasio memiliki karakteritik tinggi maka objek yang mendapatkan nilai tinggi akan mendapatkan angka 5 dan objek yang mendapatkan nilai terendah akan mendapatkan angka 1. Setelah 
mendapatkan hasil kredibilitas ratio maka dapat disimpulkan objek yang mana mendapatkan peringkat 1 sampai dengan peringkat 5 .

\section{HASIL DAN PEMBAHASAN}

Akun TikTok dari 5 Gaming Creator Yang Menginspirasi Q1-2021, diantaranya:

\section{Archer Perez}

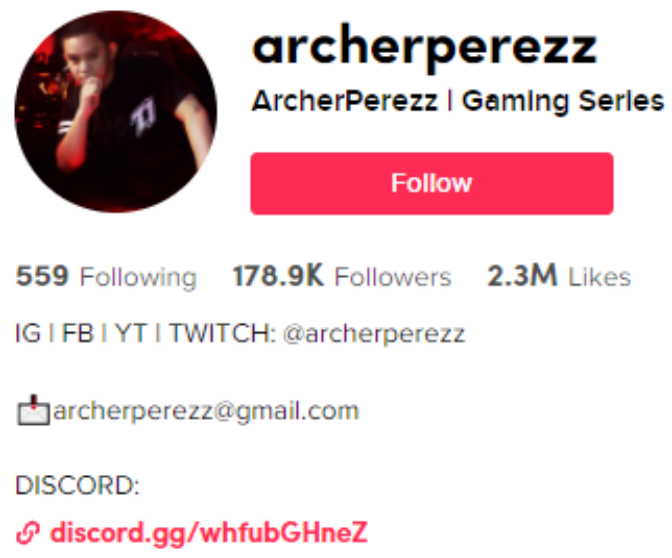

Sumber: https://www.tiktok.com/@archerperezz? (diakses pada tanggal 22-10-2021)

\section{Aya Ezmaria}

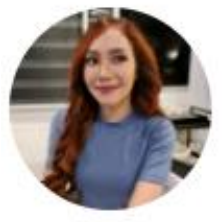

\section{ayaezmaria}

Aya Ezmarla

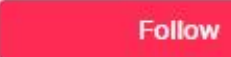

367 Following 124.9K Followers 1.9M Likes

IG I Twitch I YT I Twitter: @ayaezmaria

ayamaglanoc@gmail.com

$\checkmark$ twitch.tv/ayaezmaria

Sumber: https://www.tiktok.com/@ayaezmaria? (diakses pada tanggal 22-10-2021) 


\section{RamenStyle PH}

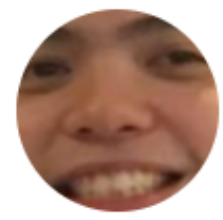

\section{ramenstyle}

RamenStyle | Streamer PH

\section{Follow}

$\mathbf{8 2 2}$ Following $\quad \mathbf{5 8 . 3} \mathrm{K}$ Followers $\mathbf{1 . 4 M}$ Likes

Streamer $\mathrm{PH}$

Twitch Partner $\checkmark$

ramenstylebusiness@gmail.com

$\mathscr{N}$ twitch.tv/ramenstyle

Sumber: https://www.tiktok.com/@ ramenstyle? (diakses pada tanggal 22-10-2021)

\section{KrisRey}

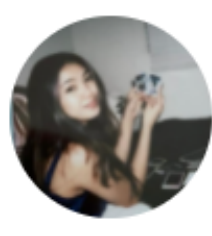

\section{krisreyx}

yt: krisrey 을
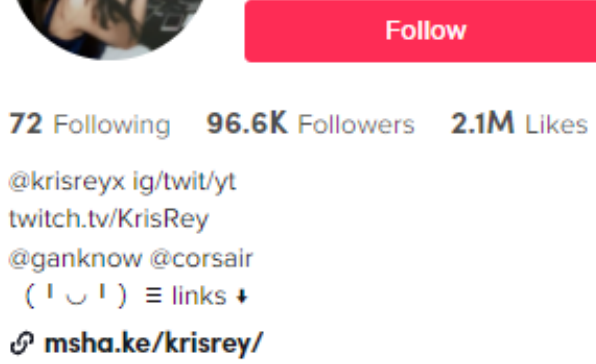

Sumber: https://www.tiktok.com/@krisreyx? (diakses pada tanggal 22-10-2021)

\section{Chuplak}

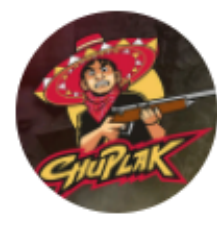

\section{chuplakz}

\section{Chuplak}

Follow

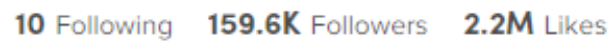

Promoting Bisdak Gaming here in Visayas and Mindanao! also in Luzon!

www.facebook.com/Chuplakz/

Sumber: https://www.tiktok.com/@ chuplakz? (diakses pada tanggal 22-10-2021) 
Dari kelima akun TikTok dari 5 Gaming Creator Yang Menginspirasi Q1-2021, peneliti menemukan nilai dari masing-masing variabel yang ada untuk menghitung rasio Video Comments to Video Views dari setiap akun. Pada akun TikTok terdapat 7 variabel, diantaranya yaitu:

1. Likes

2. Followers

3. Following

4. Video Likes

5. Video Comments

6. Video Share

7. Video Views

Dari ketujuh variabel tersebut peneliti hanya fokus untuk menemukan hasil dari 2 variabel, yaitu :

1. Video Comments

2. Video Views

Dari kedua variabel tersebut kemudian dianalisa sehingga menemukan nilai rata-rata dari variabel video comments dan variabel video views. Untuk menghitung nilai rata-rata dari variabel video comments dan variabel video views yaitu dengan cara mengambil minimal 10 postingan kemudian di hitung sehingga menemukan nilai rata-rata dari masing-masing variabel. Berikut merupakan tabel nilai rata-rata dari masing-masing gaming creator, yaitu: 
Tabel 1. Analisa Nilai Rata-Rata Nilai Variabel Video Comments dan Video Views Akun TikTok Archer Perez

\begin{tabular}{|c|c|c|}
\hline \multicolumn{3}{|c|}{ TABLE DATA } \\
\hline \multicolumn{3}{|c|}{ Archer Perez } \\
\hline No. & Comments & Views \\
\hline 01 & 175 & 697000 \\
\hline 02 & 136 & 245600 \\
\hline 03 & 114 & 260800 \\
\hline 04 & 47 & 103000 \\
\hline 05 & 23 & 109300 \\
\hline 06 & 32 & 132000 \\
\hline 07 & 148 & 311300 \\
\hline 08 & 12 & 24600 \\
\hline 09 & 78 & 283500 \\
\hline 10 & 57 & 286600 \\
\hline Total & 822 & 2453700 \\
\hline
\end{tabular}

Sumber: Pengolah Data Excel 
Tabel 2. Analisa Nilai Rata-Rata Nilai Variabel Video Comments dan Video Views Akun TikTok Aya Ezmaria

\begin{tabular}{|c|c|c|}
\hline \multicolumn{3}{|c|}{ TABLE DATA } \\
\hline \multicolumn{3}{|c|}{ Aya Ezmaria } \\
\hline No. & Comments & Views \\
\hline 01 & 34 & 103200 \\
\hline 02 & 1 & 307 \\
\hline 03 & 6 & 25200 \\
\hline 04 & 3 & 1851 \\
\hline 05 & 36 & 132800 \\
\hline 06 & 33 & 2000000 \\
\hline 07 & 26 & 99700 \\
\hline 08 & 102 & 246900 \\
\hline 09 & 3 & 13600 \\
\hline 10 & 7 & 91600 \\
\hline Total & 251 & 2715158 \\
\hline
\end{tabular}

Sumber: Pengolah Data Excel 
Tabel 3. Analisa Nilai Rata-Rata Nilai Variabel Video Comments dan Video Views Akun TikTok RamenStyle PH

\begin{tabular}{|c|c|c|}
\hline \multicolumn{3}{|c|}{ TABLE DATA } \\
\hline \multicolumn{3}{|c|}{ RamenStyle PH } \\
\hline No. & Comments & Views \\
\hline 01 & 79 & 234500 \\
\hline 02 & 35 & 249800 \\
\hline 03 & 59 & 270400 \\
\hline 04 & 35 & 270400 \\
\hline 05 & 43 & 217800 \\
\hline 06 & 71 & 269100 \\
\hline 07 & 19 & 173600 \\
\hline 08 & 11 & 2512 \\
\hline 09 & 56 & 4566 \\
\hline 10 & 15 & 45600 \\
\hline Total & 423 & 1738278 \\
\hline & Sumber: Pengolah Data Excel \\
\hline
\end{tabular}

Sumber: Pengolah Data Excel 
Tabel 4. Analisa Nilai Rata-Rata Nilai Variabel Video Comments dan Video Views Akun TikTok KrisRey

\begin{tabular}{|c|c|c|}
\hline \multicolumn{3}{|c|}{ TABLE DATA } \\
\hline \multicolumn{3}{|c|}{ KrisRey } \\
\hline No. & Comments & Views \\
\hline 01 & 45 & 147100 \\
\hline 02 & 28 & 144600 \\
\hline 03 & 17 & 6740 \\
\hline 04 & 42 & 143400 \\
\hline 05 & 28 & 165800 \\
\hline 06 & 90 & 133600 \\
\hline 07 & 60 & 148600 \\
\hline 08 & 172 & 126600 \\
\hline 09 & 25 & 131800 \\
\hline 10 & 72 & 150000 \\
\hline Total & 579 & 1298240 \\
\hline
\end{tabular}

Sumber: Pengolah Data Excel 
Tabel 5. Analisa Nilai Rata-Rata Nilai Variabel Video Comments dan Video Views Akun TikTok Chuplak

\begin{tabular}{|c|c|c|}
\hline \multicolumn{3}{|c|}{ TABLE DATA } \\
\hline \multicolumn{3}{|c|}{ Chuplak } \\
\hline No. & Comments & Views \\
\hline 01 & 60 & 364400 \\
\hline 02 & 180 & 252300 \\
\hline 03 & 92 & 330900 \\
\hline 04 & 217 & 327900 \\
\hline 05 & 74 & 261800 \\
\hline 06 & 20 & 108000 \\
\hline 07 & 133 & 447200 \\
\hline 08 & 112 & 476700 \\
\hline 09 & 30 & 242200 \\
\hline 10 & 86 & 351900 \\
\hline Total & 1004 & 3163300 \\
\hline
\end{tabular}

Sumber: Pengolah Data Excel

Tabel 6. Nilai Variabel Pada 5 Akun TikTok Gaming Creator Yang Menginspirasi Q1-2021 Q12021

\begin{tabular}{|c|c|c|c|c|c|}
\hline \multicolumn{7}{|c|}{ TABLE MASING - MASING VARIABLE } \\
\hline Variable & Archer Perez & Aya Ezmaria & RamenStyle PH & KrisRey & Chuplak \\
\hline Comments & 822 & 251 & 423 & 579 & 1004 \\
\hline Views & 2453700 & 2715158 & 1738278 & 1298240 & 3163300 \\
\hline
\end{tabular}

Pada akun TikTok terdapat 17 rasio yang relevan digunakan untuk mengukur kredibilitas pada masing-masing akun. Namun pada penelitian kali ini hanya berfokus untuk menghitung Video Comments to Video Views Ratio. Untuk menghitung kredibilitas dari masing-masing akun TikTok setiap gaming creator, peneliti menghitung dengan cara: variabel 1 akan dibagi dengan variabel 2 , sehingga ditemukan hasil analisisa dari rasio tersebut. 
Tabel 7. Hasil Perhitungan Rasio Akun TikTok

\begin{tabular}{|c|c|c|c|c|c|c|}
\hline No & Ratio & Archer Perez & $\begin{array}{c}\text { Aya } \\
\text { Ezmaria }\end{array}$ & $\begin{array}{c}\text { RamenStyle } \\
\mathrm{PH}\end{array}$ & KrisRey & Chuplak \\
\hline 1 & $\begin{array}{c}\text { Video Comments to Video } \\
\text { Views Ratio }\end{array}$ & 0.000335004 & $\begin{array}{c}9.2444 \mathrm{E}- \\
05\end{array}$ & 0.000243344 & 0.000445988 & 0.00031739 \\
\hline
\end{tabular}

Video Comments to Video Views Ratio memiliki karakteristik yang tinggi, artinya semakin tinggi nilai yang dihasilkan maka semakin baik kredibilitas dari performa akun tersebut. Untuk memberikan peringkat pada masing-masing gaming creator, peneliti memberikan angka 5 kepada creator yang mendapatkan nilai tertinggi dan angka 1 untuk gaming creator yang mendapatkan nilai terendah. Berikut merupakan tabel urutan nilai yang dihasilkan oleh masing-masing gaming creator.

Tabel 8. Hasil Perhitungan Rasio Akun TikTok

\begin{tabular}{|l|c|c|c|c|c|}
\hline \multirow{2}{*}{ Ratio } & \multicolumn{5}{|c|}{ Nilai } \\
\cline { 2 - 6 } & $\begin{array}{c}\text { Archer } \\
\text { Perez }\end{array}$ & $\begin{array}{c}\text { Aya } \\
\text { Ezmaria }\end{array}$ & $\begin{array}{c}\text { RamenStyle } \\
\text { PH }\end{array}$ & $\begin{array}{c}\text { KrisRe } \\
\mathrm{y}\end{array}$ & $\begin{array}{c}\text { Chupla } \\
\mathrm{k}\end{array}$ \\
\hline $\begin{array}{l}\text { Video Comments to Video Views } \\
\text { Ratio }\end{array}$ & 4 & 1 & 2 & 5 & 3 \\
\hline
\end{tabular}

Dari Tabel Nilai Rasio Akun TikTok 5 Gaming Creator Yang Menginspirasi Q1-2021 dapat simpulkan bahwa Aya Ezmaria mendapatkan nilai tertinggi untuk rasio Video Comments to Video Views. Sedangkan akun TikTok KrisRey mendapatkan nilai terendah untuk rasio ini. Jadi, pada penelitian ini Aya Ezmaria memiliki kredibilitas performa yang lebih baik dibandingkan dengan gaming creator yang lainnya. 


\section{KESIMPULAN}

Tujuan dari penelitian ini adalah mengetahui kredibilitas performa dari akun TikTok 5 Gaming Creator Yang Menginspirasi menggunakan Video Comments to Video Views Ratio. 5 Gaming Creator Yang Menginspirasi : Archer Perez, Aya Ezmaria, RamenStyle PH, KrisRey, dan Chuplak Indonesia. Dari kelima gaming creator tersebut dapat disimpulkan bahwa:

1. Peringkat pertama diraih oleh Aya Ezmaria dengan nilai 9.2444E-05

2. Peringkat pertama diraih oleh RamenStyle PH dengan nilai 0.000243344

3. Peringkat pertama diraih oleh Chuplak dengan nilai 0.00031739

4. Peringkat pertama diraih oleh Archer Perez dengan nilai 0.000335004

5. Peringkat pertama diraih oleh KrisRey dengan nilai terendah yaitu 0.000445988 


\section{DAFTAR PUSTAKA}

Cakra, Satria. 2021. "Dampak Tik-Tok Pada Generasi Sosial Millenial | Kumparan.Com." January 22, 2021. https://kumparan.com/satria-cakra/dampak-tik-tok-pada-generasi-sosialmillenial-1v1sLqjPUCP.

Castillo, Jonathan. 2021. "TikTok Picks 5 Gaming Creators to Inspire You to Stream - Manila Bulletin.” 2021. https://mb.com.ph/2021/08/04/tiktok-picks-5-gaming-creators-to-inspireyou-to-stream/.

Iqbal, Mansoor. 2021. "TikTok Revenue and Usage Statistics (2021) - Business of Apps." 2021. https://www.businessofapps.com/data/tik-tok-statistics/.

Maharani, Alifia. 2021. "Pengaruh Tik Tok Bagi Masyarakat Indonesia | Kumparan.Com.” 2021. https://kumparan.com/alifiaamhrn14/pengaruh-tik-tok-bagi-masyarakat-indonesia1usRwS6tobh/1.

Maryam, Siti, Ani Nur Aeni, and Program Studi PGSD Kampus Sumedang Jalan Mayor Abdurachman No. 2016. "PENDEKATAN EKSPLORATIF UNTUK MENINGKATKAN KEMAMPUAN REPRESENTASI MATEMATIS DAN KEPERCAYAAN DIRI SISWA." Jurnal Pena Ilmiah 1 (1): 551-60. https://doi.org/10.23819/PI.V1I1.2984.

Purnamasari, Nurjihan Pricillia, and Ririn Puspita Tutiasri. 2021. "Analisis Resepsi Remaja Perempuan Terhadap Gaya Hidup Berbelanja Fashion Melalui Tayangan Video 'Belanja Gak Aturan' Dalam Akun Tiktok @handmadeshoesby.” Jurnal Representamen 7 (01). https://doi.org/10.30996/REPRESENTAMEN.V7I01.5129. 